\title{
0377 PREVALENCE OF BICYCLE HELMET USE AMONG ELEMENTARY SCHOOL STUDENTS IN FOUR CANADIAN CITIES
}

T Middaugh-Bonney, I Pike, M Brussoni, S Piedt, A Macpherson* Correspondence: School of Kinesiology and Health Science, York University Faculty of Graduate Studies, York University, 222 Norman Bethune College, 4700 Keele Street, Toronto, Ontario, M3J 1P3, Canada

10.1136/ip.2010.029215.377

Introduction Bicycle-related injuries are an important cause of hospitalisation among Canadian children. There is variation in the nature and enforcement of bicycle helmet laws in Canada. The Canadian Injury Indicators Development Team was established to define and evaluate key indicators, including helmet use and bicycle helmet laws.

Purpose To assess the prevalence of helmet use in elementary school aged children in four Canadian cities representing varied geographic and socioeconomic settings.

Methods Observations were made at schools in Halifax, Toronto, Barrie and Vancouver. Schools were identified using school board websites and DMTI, a company that partners with universities to disseminate spatial data. Schools were classified into quintiles based on the after-tax income of their census tract (2006 census). Trained observers attended each site at the beginning of the school day in May/June 2009. Information on the sex, helmet use, correct helmet use and group riding were documented.

Results 397 observations were made at 91 schools. The helmet use rate was $83 \%$ across the four cities. $68 \%$ of those riding bicycles were males and $47 \%$ of children rode in a group. Group influence on helmet use varied by province. The influence of socioeconomic status (SES) on helmet use also varied. Vancouver's poorest neighbourhoods had the most riders (42\%), whereas Toronto had the most of riders in the richest neighbourhoods (39\%).

Conclusion There is variation in helmet use across Canadian cities generally, and by SES specifically. Helmet use rates were higher in the medium sized city (Barrie) compared to the other, larger cities. 